\title{
Coordinated lidar observations of Saharan dust over Europe in the frame of EARLINET-ASOS project during CALIPSO overpasses: a strong dust case study analysis with modeling support
}

\begin{abstract}
A. Papayannis ${ }^{\mathrm{a}, *}$, V. Amiridis ${ }^{\mathrm{b}}$, L. Mona ${ }^{\mathrm{c}}$, R. E. Mamouri ${ }^{\mathrm{a}}$, A. Apituley ${ }^{\mathrm{d}}$, L. Alados-Arboledas ${ }^{\mathrm{e}}$, D. Balis ${ }^{f}$, A. Chaikovski ${ }^{g}$, F. De Tomasi ${ }^{\text {h }}$, I. Grigorov ${ }^{i}$, O. Gustafsson ${ }^{j}$, H. Linne ${ }^{k}$, I. Mattis ${ }^{l}$, V. Mitev $^{\mathrm{m}}$, F. Moleron ${ }^{\mathrm{n}}$, D. Müller, ${ }^{\mathrm{l}, \mathrm{o}}$, D. Nicolae ${ }^{\mathrm{p}}$, C. Pérez ${ }^{\mathrm{q}}$, A. Pietruczuk ${ }^{\mathrm{r}}$, J.P . Putaud ${ }^{\mathrm{s}}$, F. Ravetta $^{t}$, V. Rizi ${ }^{u}$, F. Schnell ${ }^{\mathrm{y}}$, M. Sicard ${ }^{\mathrm{w}}$, V. Simeonov ${ }^{\mathrm{x}}$, K. Stebel ${ }^{\mathrm{y}}$, T. Trickl ${ }^{\mathrm{z}}$, G. D'Amico ${ }^{\mathrm{c}}$, G. Pappalardoc and X. Wang
\end{abstract}

${ }^{a}$ National Technical University of Athens-NTUA, Physics Department, Athens, Greece

${ }^{\mathrm{b}}$ Institute for Space Applications and Remote Sensing, National Observatory of Athens, Greece

${ }^{c}$ Istituto di Metodologie per l'Analisi Ambientale-CNR, Potenza, Italy

${ }^{\mathrm{d}}$ National Institute for Public Health and the Environment, Bilthoven, Netherlands

e Universidad de Granada, Granada, Spain

${ }^{\mathrm{f}}$ Laboratory of Atmospheric Physics, Univ. of Thessaloniki, Thessaloniki, Greece

g Institute of Physics, National Academy of Sciences of Belarus, Minsk, Belarus

${ }^{\mathrm{h}}$ University of Lecce, Physics Department, Lecce, Italy

${ }^{\mathrm{i}}$ Institute of Electronics, Bulgarian Academy of Sciences, Sofia, Bulgaria

${ }^{\mathrm{j}}$ Swedish Defence Research Agency (FOI), Linköping, Sweden

${ }^{\mathrm{k}}$ Max-Planck-Institut für Meteorologie, Hamburg, Germany

${ }^{1}$ Leibniz Institute for Tropospheric Research, Leipzig, Germany

${ }^{\mathrm{m}}$ Observatory of Neuchâtel, Switzerland

${ }^{\mathrm{n}}$ Atmospheric Pollution Unit Environmental Department CIEMAT, Madrid, Spain

${ }^{\circ}$ Atmospheric Remote Sensing Laboratory, Depart. Environmental Science and Engineering, Gwangju Institute of Science and Technology (GIST), Gwangju, Republic of Korea

${ }^{\mathrm{p}}$ National Institute of R\&D for Optoelectronics, Bucharest, Romania

${ }^{\mathrm{q}}$ Earth Sciences Division, Barcelona Supercomputing Centre, Barcelona, Spain

${ }^{\mathrm{r}}$ Institute of Geophysics, Polish Academy of Sciences, Warsaw, Poland

${ }^{\mathrm{s}} \mathrm{JRC}$ Institute for Environment and Sustainability, Ispra, Italy

${ }^{t}$ Service d'Aéronomie-IPSL, Université Pierre et Marie Curie (UP6), Paris, France

${ }^{\mathrm{u} C E T E M P S}$ and Dipartimento di Fisica, Università Degli Studi - L'Aquila, L'Aquila, Italy

${ }^{v}$ Meteorologisches Institut der Universität München, Munich, Germany

${ }^{\mathrm{w}}$ Remote Sensing Laboratory, Universitat Politecnica di Catalunya, Barcelona, Spain

${ }^{\mathrm{x}}$ Ecole Polytechnique Federale de Lausanne, Switzerland

${ }^{\mathrm{y}}$ Norwegian Institute for Air Research, Tromsö, Norway

${ }^{\mathrm{z}}$ Forschungszentrum Karlsruhe, IMK-IFU, Garmisch-Partenkirchen, Germany

${ }^{\varnothing} \mathrm{CNISM}$ and Dipartimento di Scienze Fisiche-Università di Napoli Federico II, Napoli, Italy

*apdlidar@central.ntua.gr, phone: +302107722992, fax: +302107722928 


\begin{abstract}
Coordinated lidar observations of Saharan dust over Europe are performed in the frame of the EARLINETASOS (2006-2011) project, which comprises 25 stations: 16 Raman lidar stations, including 8 multiwavelength (3+2 station) Raman lidar stations, are used to retrieve the aerosol microphysical properties. Since the launch of CALIOP, the two-wavelength lidar on board the CALIPSO satellite (June 2006) our lidar network has been performing correlative aerosol measurements during CALIPSO overpasses over the individual stations. In our presentation, we report on the correlative measurements obtained during Saharan dust intrusions in the period from June 2006 to June 2008. We found that the number of dust events is generally greatest in late spring, summer and early autumn periods, mainly in southern and south-eastern Europe. A measurement example is presented that was analyzed to show the potential of a ground based lidar network to follow a dust event over a specific study area, in correlation with the CALIOP measurements. The dust transport over the studied area was simulated by the DREAM forecast model. Cross-section analyses of CALIOP over the study area were used to assess the model performance for describing and forecasting the vertical and horizontal distribution of the dust field over the Mediterranean. Our preliminary results can be used to reveal the importance of the synergy between the CALIOP measurement and the dust model, assisted by ground-based lidars, for clarifying the overall transport of dust over the European continent.
\end{abstract}

Keywords: CALIPSO, EARLINET, lidar, dust, aerosols, DREAM, Hysplit

\title{
1. INTRODUCTION
}

Mineral dust is an important component of the atmospheric aerosol loading. According to Kinne et al ${ }^{[1]}$ mineral dust accounts for about $75 \%$ of the global aerosol mass load and $25 \%$ of the global aerosol optical depth. The African continent, especially its northern part (Sahara desert), the Saudi Arabian regions, as well as the Asian continent (eastern areas), are the main sources of dust around the globe ${ }^{[2,3,4]}$. However, the estimations of the Saharan dust emissions fluctuate between 130 and $1600 \mathrm{Tg} / \mathrm{year}^{[4-6]}$. Mineral dust particles play an important role in the Earth's radiation balance and climate, by acting as cloud condensation nuclei $(\mathrm{CCN})$ and thereby determine the concentration of the initial droplets, albedo, precipitation formation and lifetime of clouds ${ }^{[7-8]}$. The latest report of the Intergovernmental Panel on Climate Change (IPCC) $)^{[9]}$ only considers the dust-related anthropogenic effect which is about $20 \%$ of the total dust radiative effect. Therefore the role of the natural dust particles becomes very important in radiative forcing issues. According to that report the climatic role of dust aerosol is now better quantified than in the previous IPCC report ${ }^{[10]}$. Thus, a total direct aerosol radiative forcing combined across all aerosol types is now be given as $-0.5 \pm 0.4 \mathrm{~W} / \mathrm{m}^{2}$, with a medium-low level of scientific understanding. However, between the two IPCC reports the overall uncertainties in the radiative forcing effect of dust (anthropogenic and natural) remain the same and still very high.

These uncertainties can only be reduced by better quantifying the vertical and horizontal distribution of dust in the globe. Sokolik et al. ${ }^{[11]}$ mentioned that the existing uncertainties are caused in part by the limited data on dust climatology and our incomplete understanding of the processes responsible for the production, transport, physical and chemical evolution, and removal of mineral aerosols at various space scales and timescales. Lidar network measurements of the vertical distribution of the optical properties of dust can contribute to such quantification. The co-existence of lofted Saharan dust plumes over areas with significant anthropogenic aerosol sources in the boundary layer ${ }^{[12]}$, does not allow their accurate separation, when examining satellite or ground-based columnar measurements. Lidar measurements are in that sense essential since they provide very valuable information on the vertical distribution of the optical properties of aerosols of desert origin. A multi-step approach for the discrimination between the different aerosol types and more specifically, for the dust aerosols detection has been adopted: 1) identification of the dust layers, 2) in addition to step 1, air mass backtrajectories are calculated to identify the aerosol source region, 3) in addition to steps 1 and 2, and depending on the lidar station, the aerosol layers are characterized by the use of the Angström exponent, the depolarisation and lidar ratio profiles. 


\section{INSTRUMENTATION AND METHODS}

\subsection{EARLINET Network: Lidar measurements methodology}

Coordinated lidar observations of Saharan dust over Europe are performed in the frame of the EARLINET (2000-2003) and the EARLINET-ASOS (2006-2011) projects ${ }^{[13-14]}$. At present, EARLINET-ASOS consists of 25 stations: 16 Raman lidar stations, including 8 multi-wavelength $(3+2$ station) Raman lidar stations which are used to retrieve aerosol optical and microphysical properties ${ }^{[15-16]}$. Correlative EARLINET-ASOS and CALIPSO ${ }^{[17]}$ measurements are performed within the ESA-CALIPSO study, which is based on observations at 16 EARLINET stations over a period of 18 months ${ }^{[18-20]}$. Measurements are performed at all stations within $80 \mathrm{~km}$ from the overpasses and additionally at the lidar station which is closer to the actually overpassed site. If a multi-wavelength Raman lidar station is overpassed then also the next closest $3+2$ station performs a measurement. Figure 1 shows the EARLINET stations which perform the correlative EARLINET-ASOS and CALIPSO measurements, distributed in four different clusters (regions): Central Europe (Germany, The Netherlands), Western Mediterranean (Spain), Central Mediterranean (Italy) and Eastern Mediterranean (Greece, Bulgaria and Romania). In addition two other stations are located in Eastern Europe (Poland and Belarus).

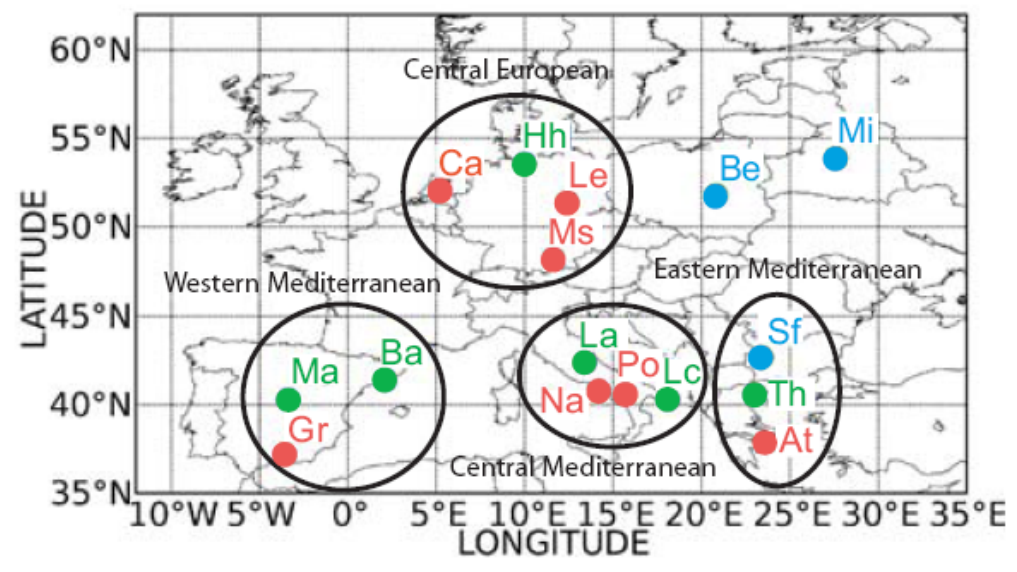

Figure 1. EARLINET stations performing correlative EARLINET-ASOS and CALIPSO measurements. Red dots show the highperformance core stations (At-Athens, Ca-Cabauw, Gr-Granada, Le-Leipzig, Ms-Maisach, Na-Napoli, Po-Potenza). Green and blue dots represent contributing stations (Ba-Barcelona, Be-Belsk, Hh-Hamburg, La-L'Aquila, Lc-Lecce, Ma-Madrid, Mi-Minsk, ThThessaloniki, Sf-Sofia).

A set of criteria has been applied to characterize an aerosol layer as a "Saharan dust" profile. The first criterion was that the aerosol profile should contain at least one distinct aerosol layer above the PBL retrieved following the EARLINET criterion $^{[21]}$. The second criterion was that the specific aerosol layer should originate from the Saharan region. The origin of this layer was identified on the base of the three-dimensional four-day air mass back trajectory analysis. In some very limited cases, a longer air mass back-trajectory analysis (up to 5-7 days) was needed due to more complex meteorological conditions or long, indirect advection (e.g. via the Atlantic Ocean) involved in the dust transport processes. In order to verify that the vertical level at which the trajectory passed over the desert area contained mineral dust, we used the DREAM model forecasts as a third criterion, which took into account convective activities over the Saharan area.

EARLINET and EARLINET-ASOS showed that multiple aerosol dust layers of variable thickness $(300-7500 \mathrm{~m})$ are usually observed ${ }^{[14]}$. The center of mass of these layers was located in altitudes between $850-8000 \mathrm{~m}$. However, the mean thickness of the dust layer typically stayed around 1500-3400 $\mathrm{m}$ and the corresponding mean center of mass ranged from 2500 to $6000 \mathrm{~m}$. Mean aerosol optical depths (AOD), extinction-to-backscatter ratios (lidar ratios, LR) and linear depolarization ratios of desert aerosols ranged from 0.1 to 0.25 at the wavelength of 355 or $351 \mathrm{~nm}, 30$ to 80 sr at 355 or $351 \mathrm{~nm}$ and 10 to $25 \%$ at $532 \mathrm{~nm}$ respectively, within the lofted dust plumes. In these plumes typical Saharan dust backscatter coefficients ranged from 0.5 to $2 \mathrm{Mm}^{-1} \mathrm{sr}^{-1}$. Southern European stations presented higher variability of the LR 
values and the backscatter-related Ångström exponent values (BRAE) (LR: 20-100 sr; BRAE: -0.5 to 3) than northern ones (LR: $30-80$ sr; BRAE: -0.5 to 1).

\subsection{Air mass trajectories}

The German Weather Service (DWD) provided 4-day backward trajectories at each EARLINET lidar station for two arrival times per day and for six arrival pressure levels between 200 and $975 \mathrm{hPa}^{[13]}$. Additionally, 4-day (and some times longer) air mass back trajectories were computed using the National Oceanic and Atmospheric Administration (NOAA) HYbrid Single-Particle Lagrangian Integrated Trajectory (HYSPLIT-4) model ${ }^{[22]}$ from the NOAA Air Resources Laboratory, Silver Spring, Maryland, USA. The HYSPLIT trajectories were computed at several altitudes (mainly between 2000 and $6000 \mathrm{~m}$ ) every six hours for the period May 2000 to December 2002. Trajectory information was also derived from the ten-day NOAA Climate Monitoring and Diagnostics Laboratory (CMDL) model (http://www.cmdl.noaa.gov/traj/plots/zug.html) and, in selected cases, from the FLEXTRA model (http://zardoz.nilu.no/ andreas/flextra+flexpart.html). Usually the deviation between the calculated and the actual track of an air parcel is of the order of $10-20 \%$ of the travel distance. This is because the accuracy depends on the interpolation of meteorological data, on assumptions of vertical transport, on wind field errors, on truncation errors and on the synoptic condition, where higher wind speeds give better accuracies of the trajectories [Stohl, 1998]. Nevertheless, trajectories provide a useful tool to characterize patterns in the large-scale motion.

\subsection{DREAM dust model}

The dust forecast is based on the operational outputs of the DREAM (operated then at Malta at the Centre on Insular Coastal Dynamics-ICOD and now in Barcelona, Spain: http://www.bsc.es/projects/earthscience/DREAM/). DREAM simulates or predicts the three-dimensional field of the dust concentration in the troposphere ${ }^{[23]}$ taking into account all major processes of the dust life cycle, such as dust production, horizontal and vertical diffusion and advection and wet and dry deposition. The model also includes the effects of the particle size distribution on aerosol dispersion. In DREAM the dust mass is described by particles with four sizes, resulting from the structure of desert soils based on the content of clay, small silt, large silt and sand. The model numerically solves the Euler-type mass partial differential equation by integrating it spatially and temporally. The dust production is parameterized using the near-surface wind and thermal conditions, as well as soil features. The dust production mechanism is based on the viscous/turbulent mixing, shear-free convection diffusion, and soil moisture.

\section{RESULTS AND DISCUSSION}

As stated before we report on correlative EARLINET-ASOS and CALIOP measurements obtained during Saharan dust intrusions in the period from June 2006 to June 2008. To get a more representative view of the monthly variation (mean values) of the forecasted (by DREAM), the observed Saharan dust days by lidar inside the Eastern Mediterranean cluster and the respective mean number of coincident CALIOP overpasses we show in Figure 2 the relevant results for the case of the Athens station. The under-sampling of the dust events by the lidar observations in Athens with respect to the "model-forecast" days could be explained by the fact that the lidar measurements could not be performed when unfavourable meteorological conditions prevailed (low-lying overcast or rainy conditions) over Athens or when technical problems occurred to the lidar system. Therefore, for the Athens station, we see that the number of dust events is generally greatest in late spring, summer and early autumn periods. A more representative overview of the seasonal variation of the Saharan dust events over the European continent is given by Papayannis et al. ${ }^{[14]}$.

As stated before we focus on the period of dust intrusion in Europe from May 27 to 30, 2008 to show the potential of a ground based lidar network to follow a dust event over a specific study area, in correlation with the CALIOP measurements. The dust transport over the studied area was simulated by the DREAM forecast model which predicts the 3-D field of the dust concentration in the troposphere taking into account all major processes of the dust life cycle. Crosssection analyses of CALIOP over the study area were used to assess the model performance for describing and forecasting the vertical and horizontal distribution of the dust field over the Mediterranean. In Fig. 3 we show the CALIPSO overpasses around 00:44-01:20 UTC (black lines) over the European continent for the selected period (May 27 to 30,2008$)$ together with the aerosol optical depth-AOD at $550 \mathrm{~nm}$ and the wind field at $3000 \mathrm{~m}$ simulated by DREAM for 00:00 or 12:00 UTC. The location of the EARLINET stations is shown by the red dots. 


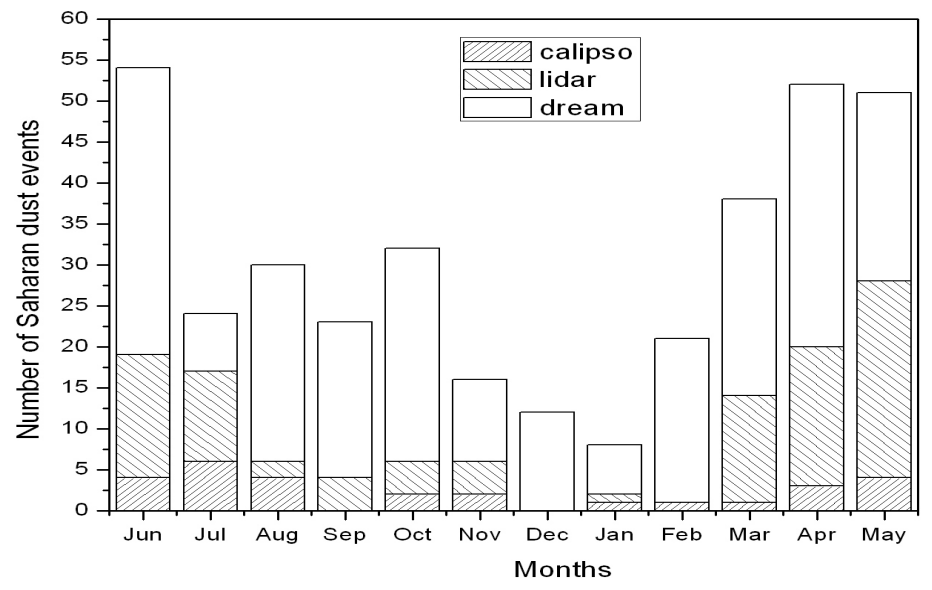

Figure 2. Mean monthly variation of forecasted (by DREAM), observed Saharan dust days by lidar over Athens and the respective mean number of coincident CALIOP overpasses.
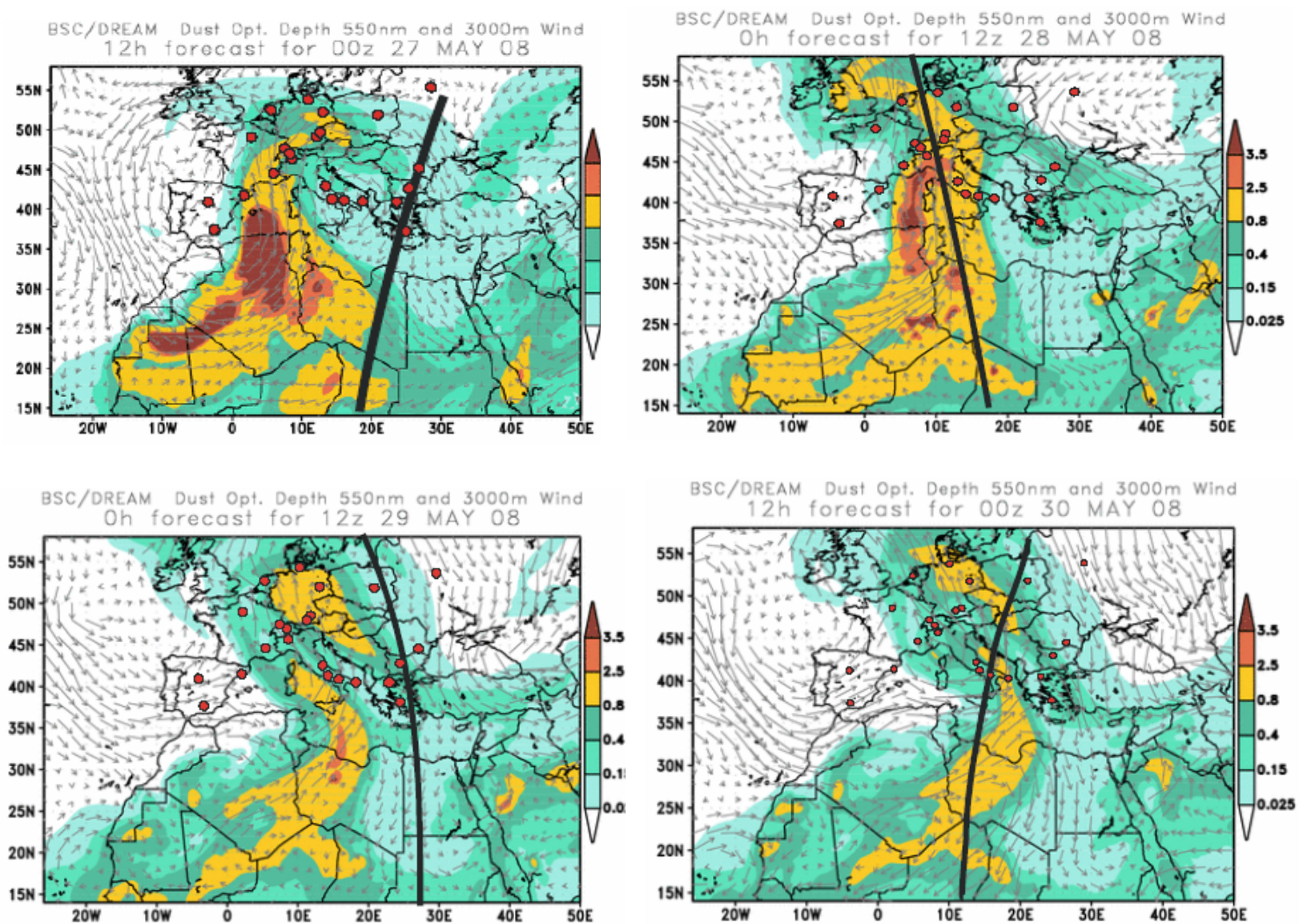

Figure 3. CALIPSO overpasses (black line) over the European continent for the selected period (May 27 to 30, 2008) together with the aerosol optical depth-AOD at $550 \mathrm{~nm}$ and the wind field at $3000 \mathrm{~m}$ simulated by DREAM for 00:00 or 12:00 UTC. The location of the EARLINET stations is shown by the red dots. 

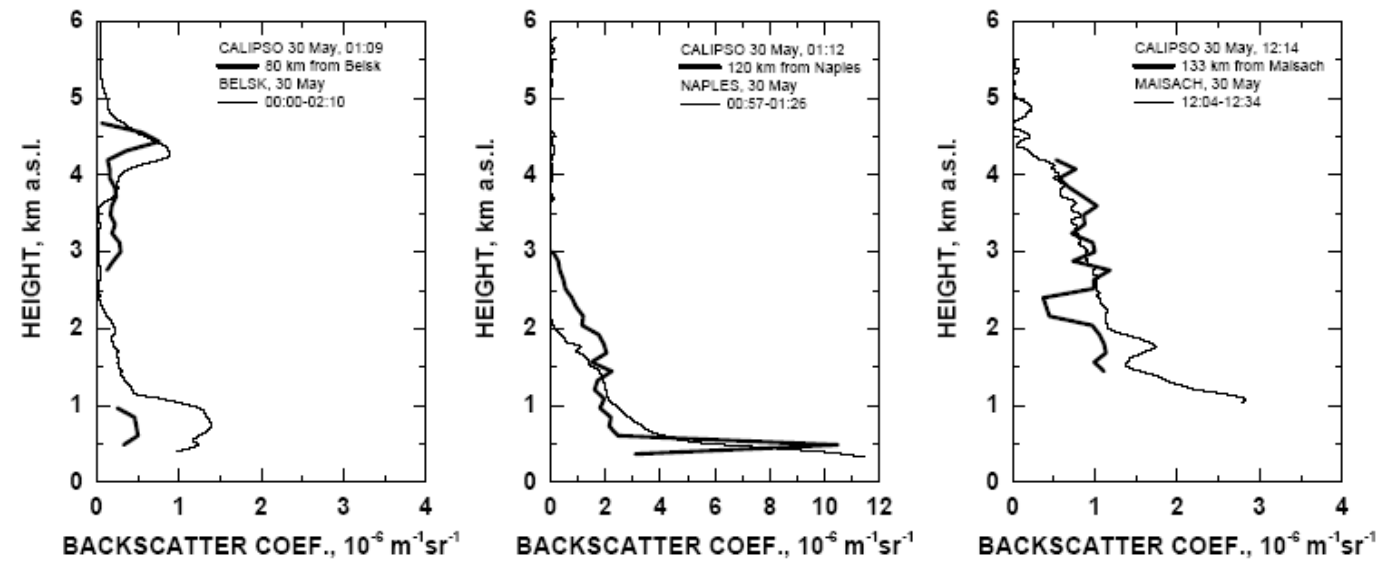

Figure 4. Comparison of CALIPSO and EARLINET 532-nm backscatter coefficient profiles taken over Belsk, Napoli, and Maisach on May 30, 2008.

In Fig. 4 we show the direct comparison of level-2 (L2) CALIPSO lidar data with EARLINET data in terms of the vertical profiles of aerosol backscatter coefficient obtained at $532 \mathrm{~nm}$ over three selected stations during the overpasses over Belsk, Napoli and Maisach on May 30, 2008. Taking into account the spatial and temporal in-homogeneity of the dust plume and the typical distances between the CALIPSO ground track and the EARLINET stations (between 80-130 $\mathrm{km}$ ), a good agreement between the aerosol profiles is generally found. More detailed analysis can be found in Mamouri et al. ${ }^{[24]}$ and Pappalardo et al. ${ }^{[20]}$. In the following we will focus on the dust transport over Europe using vertical crosssection analyses of CALIPSO, aerosol profiles over selected lidar stations and simulations of the DREAM forecast model to assess the model performance for describing and forecasting the vertical and horizontal distribution of the dust field over the Mediterranean region. Thus, Fig. 5 (upper left part) shows the vertical cross-section of aerosols obtained by CALIPSO (in terms of the attenuated aerosol backscatter lidar signal) at $1064 \mathrm{~nm}$ from 00:36-00:49 UTC on May 27, 2008 over the ground-track (black line) shown in Fig. 3 (upper left part). The white line in Fig. 5 (upper left) represents the location of the EARLINET lidar station in Athens, while the black line in the upper right part of the same figure shows the time of measurement over the station of Athens (range-corrected signal in arbitrary units obtained at $1064 \mathrm{~nm}$ ) which coincides with the CALIPSO overpass. The lower part of Fig. 5 is the vertical cross-section of the dust simulated by DREAM along the CALIPSO ground-track shown in Fig. 3 (upper left part).

Similarly to Fig. 5, Fig. 6 (upper left part) shows the vertical cross-section of aerosols obtained by CALIPSO (in terms of the attenuated backscatter signal) at $1064 \mathrm{~nm}$ from 12:26-12:40 UTC on May 28, 2008 over the ground-track (black line) shown in Fig. 3 (upper right part). The white lines in Fig. 6 (upper left) represent the location of the EARLINET lidar stations (left line: Munich, right line: Leipzig), while the white lines in the right-hand figures of Fig. 6, show the time of measurement over the station of Munich and Leipzig (range-corrected signals in arbitrary units obtained at $1064 \mathrm{~nm}$ ) which coincide with the CALIPSO overpass. The lower part of Fig. 6 is again the vertical cross-section of the dust simulated by DREAM along the CALIPSO ground-track shown in Fig. 3 (upper right part). Comparing again the aerosol profiles obtained over Munich and Leipzig by CALIPSO (white lines in Fig. 6 upper left part) with the ones obtained by the ground stations over these sites (white lines of Fig. 6 right-hand part) we see that all instruments delineate the distinct aerosol layering at $5 \mathrm{~km}$ height, and the presence of clouds at about $9-12 \mathrm{~km}$ height. In addition, the DREAM model is able to retrieve, at least qualitatively, the intense dust layer seen by CALIPSO between ground and $5 \mathrm{~km}$ height (see one large cross section with two black arrows), along the CALIPSO trajectory. 

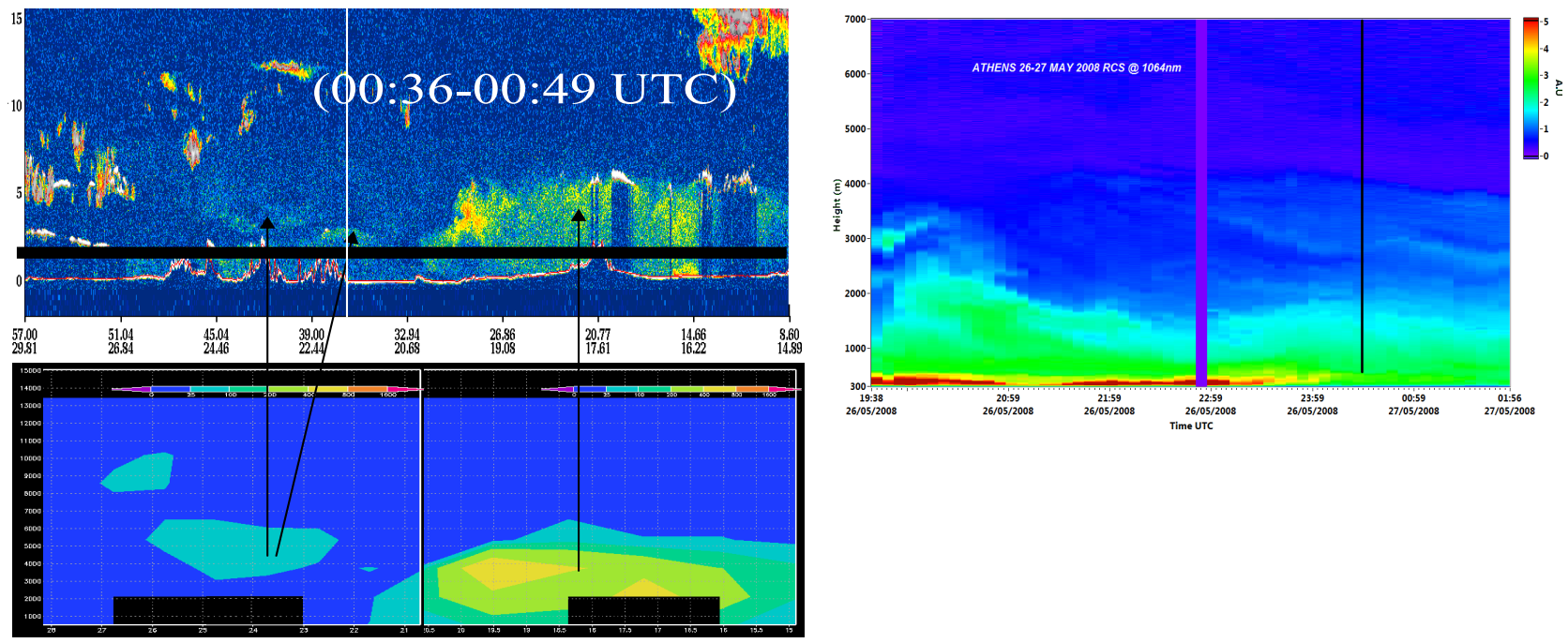

Figure 5. Upper left part: vertical cross-section of aerosols obtained by CALIPSO (in terms of the attenuated aerosol backscatter lidar signal) at $1064 \mathrm{~nm}$ from 00:36-00:49 UTC on May 27, 2008 (vertical axis: in km, horizontal axis: latitude and longitude in deg). Lower left part: vertical cross-section of aerosol concentration (in $\mathrm{ug} / \mathrm{m}^{3}$ ) obtained by DREAM (vertical axis: in $\mathrm{m}$, horizontal axis: longitude in deg). Upper right part: vertical cross-section of aerosols obtained over Athens by lidar ground station (in terms of rangecorrected lidar signal at $1064 \mathrm{~nm}$ in arbitrary units) from 26 to 27 May 2008 (19:38 - 01:56 UTC).
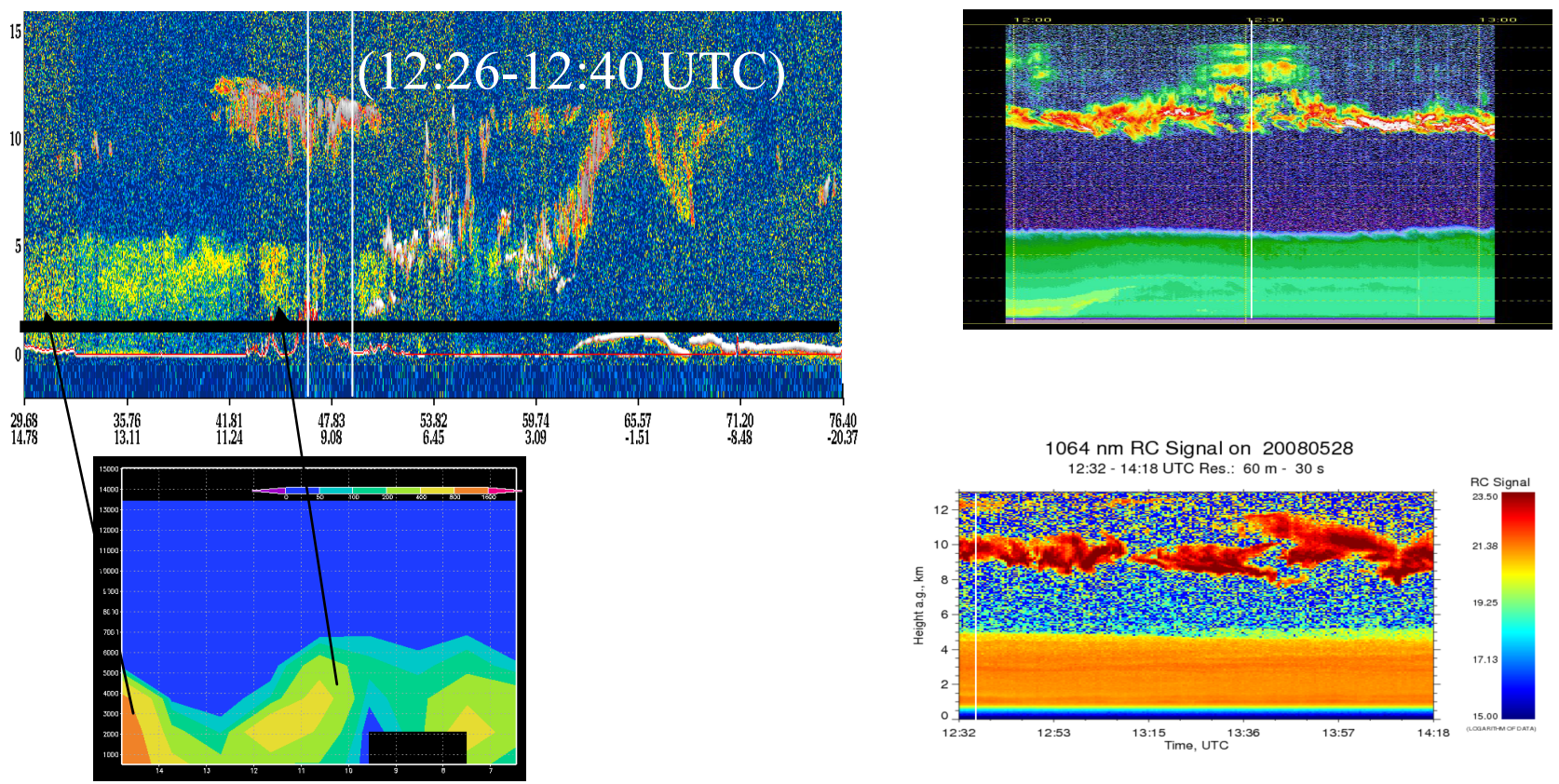

Figure 6. Upper left part: vertical cross-section of aerosols obtained by CALIPSO (in terms of the attenuated aerosol backscatter lidar signal) at $1064 \mathrm{~nm}$ from 12:26-12:40 UTC on May 28, 2008 (vertical axis: in km, horizontal axis: latitude and longitude in deg). Lower left part: vertical cross-section of aerosol concentration (in $\mathrm{ug} / \mathrm{m}^{3}$ ) obtained by DREAM (vertical axis: in $\mathrm{m}$, horizontal axis: longitude in deg). Right-hand side: vertical cross-section of aerosols obtained over Munich (upper figure) and Leipzig (lower figure) by lidar ground station (in terms of range-corrected lidar signal at $1064 \mathrm{~nm}$ in arbitrary units) on May 28, 2008 (12:32 - 14:18 UTC).

Similarly to Figs. 5 and Fig. 6, Fig. 7 (upper left part) shows the vertical cross-section of aerosols obtained by CALIPSO (in terms of the attenuated backscatter signal) at 1064 nm from 01:07-01:21 UTC on May 30, 2008 over the ground-track (black line) shown in Fig. 3 (lower right part). The white lines in Fig. 7 (upper left) represent the location of the 
EARLINET lidar stations (left line: Belsk, right line: Potenza), while the white lines in the right-hand figures of Fig. 7, show the time of measurement over the station of Belsk and Potenza (range-corrected signals in arbitrary units obtained at $1064 \mathrm{~nm}$ ) which coincide with the CALIPSO overpass. The lower part of Fig. 7 is again the vertical cross-section of the dust simulated by DREAM along the CALIPSO ground-track shown in Fig. 3 (lower right part). Comparing again the aerosol profiles obtained over Belsk and Potenza by CALIPSO (white lines in Fig. 7 upper left part) with the ones obtained by the ground stations over these sites (white lines of Fig 7 right-hand part) we see that all instruments delineate the extended aerosol layering around 2-2.5 km height, while in the case of Belsk it extends up to $4 \mathrm{~km}$ height. The presence of clouds over Belsk is clearly visible at about 10-12 km height in the data obtained by both CALIPSO and the ground station. In addition, the DREAM model is able to retrieve, at least qualitatively, the intense dust layers seen by CALIPSO between ground and 5-6 km height, although in some areas it goes down to $0.5-2 \mathrm{~km}$ height along its trajectory. The three black arrows in Fig. 7 (lower left part) show three selected areas along the CALIPSO trajectory, which are very well simulated (at least qualitatively) by DREAM showing distinct patterns of aerosols.

As a conclusion, in all cases the comparison between the CALIPSO and the EARLINET aerosol vertical profiles shows a good agreement concerning the location - in time and space - of the various dust layers detected. In addition, the DREAM model is able to reproduce, at least qualitatively, the dust aerosol vertical cross sections observed by CALIPSO along its trajectory.
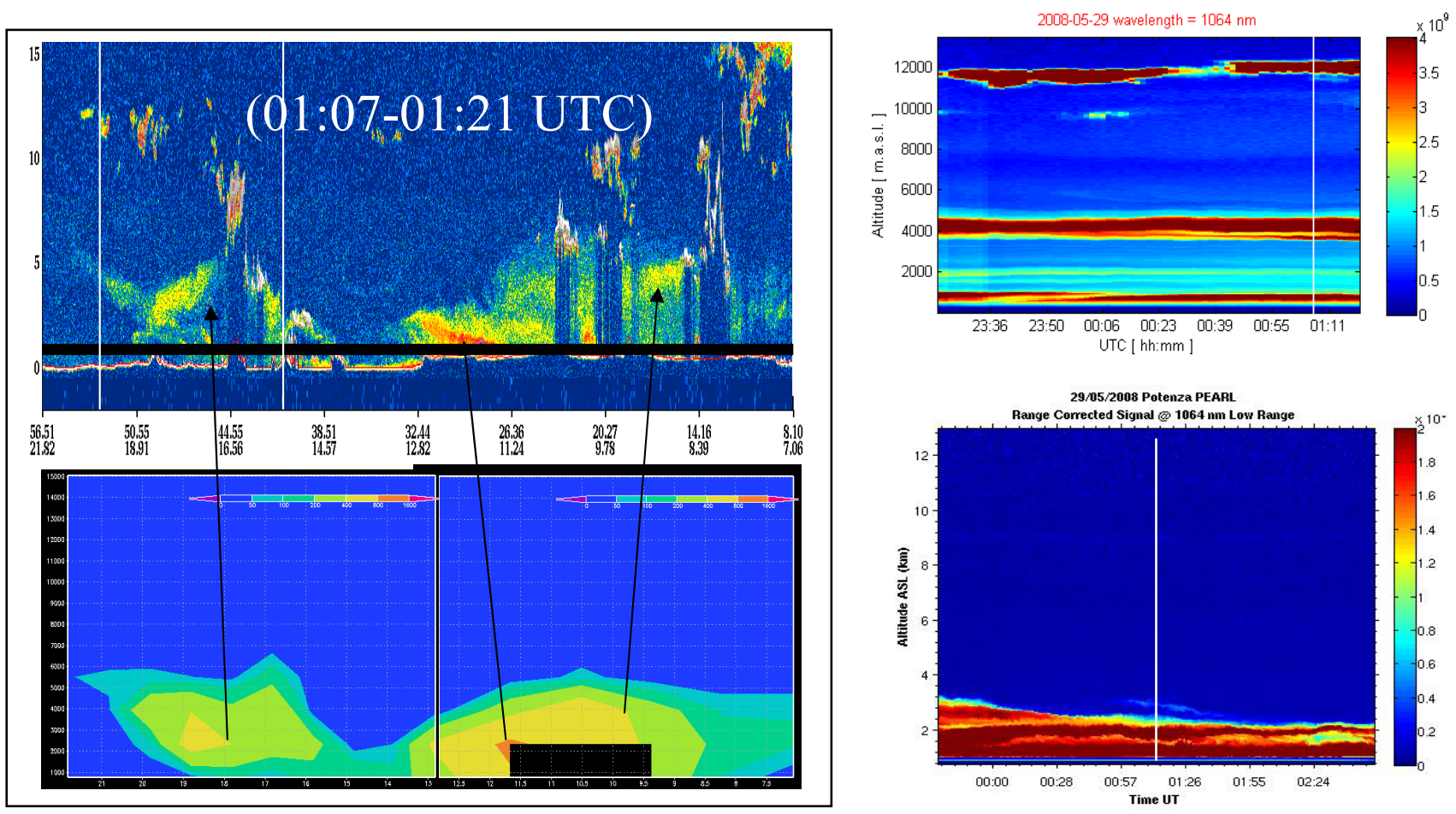

Figure 7. Upper left part: vertical cross-section of aerosols obtained by CALIPSO (in terms of the attenuated aerosol backscatter lidar signal) at $1064 \mathrm{~nm}$ from 01:07-01:21 UTC on May 30, 2008 (vertical axis: in km, horizontal axis: latitude and longitude in deg). Lower left part: vertical cross-section of aerosol concentration (in $\mathrm{ug} / \mathrm{m}^{3}$ ) obtained by DREAM (vertical axis: in $\mathrm{m}$, horizontal axis: longitude in deg). Right-hand side: vertical cross-section of aerosols obtained over Belsk (upper figure) and Potenza (lower figure) by lidar ground station (in terms of range-corrected lidar signal at 1064 nm in arbitrary units) from May 29 to 30, 2008 (23:00 - 02:30 UTC).

\section{CONCLUSIONS}

In this paper, we reported on correlative measurements obtained during Saharan dust intrusions in the period from June 2006 to June 2008. We found that the number of dust events is generally greatest in late spring, summer and early autumn periods, mainly in southern and south-eastern Europe. We focused on the period of dust intrusion in Europe from May 27 to 30, 2008. The dust transport over the studied area was simulated by the DREAM forecast model which predicts the 3-D field of the dust concentration in the troposphere taking into account all major processes of the dust life 
cycle. Cross-section analyses of CALIOP over the study area were used to assess the model performance for describing and forecasting the vertical and horizontal distribution of the dust field over the Mediterranean. We found good agreement between the CALIPSO and the EARLINET aerosol vertical profiles concerning the location - in time and space - of the various dust layers detected. In addition, we found that the DREAM model is able to reproduce, at least qualitatively, the dust aerosol vertical cross sections observed by CALIPSO along its trajectory. In this paper, we showed the potential of a ground based lidar network to follow a dust event over a specific study area, in correlation with the CALIOP measurements. Our preliminary results can be used to reveal the importance of the synergy between the CALIOP measurement and the dust model, assisted by ground-based lidars, for clarifying the overall transport of dust over the European continent.

\section{FUTURE WORK}

Our preliminary results, for the European continent, which are similar to those presented by Huang et al. ${ }^{[25]}$, Uno et al. ${ }^{[26]}$ and recently by Eguchi et al. ${ }^{[27]}$ in the Asian continent, can be used to reveal the importance of the synergy between the CALIOP measurement and the dust model, assisted by ground-based lidars, for clarifying the overall transport of dust over the European continent.

\section{ACKNOWLEDGMENTS}

This work was financed by the EU-FP6 EARLINET-ASOS project (RICA-025991) and the European Space Agency (ESA) under contract $\mathrm{AO} / 1-5502 / 07 / \mathrm{NL} / \mathrm{HE}$.

\section{REFERENCES}

[1] Kinne, S., et al., "An AeroCom initial assessment: Optical properties in aerosol component modules of global models", Atmos. Chem. Phys., 6, 1815-1834 (2006).

[2] Duce, R.A., "Sources, distribution and fluxes of mineral aerosols and their relationship to climate". [Aerosol Forcing on Climate], Carlson, R.J., and Heintzenberg, J., (Eds.), Wiley, New York, 43-72 (1995).

[3] Marticorena, B., Bergametti, G., Aumont, B., Callot, Y., N’Doumé, C. and Legrand, M., “ Modeling the atmospheric dust cycle: 2. Simulation of Saharan sources”, J. Geophys. Res., 102, 4387- 4404 (1997).

[4] Engelstaedter, S., and Washington, R., "Temporal controls on global dust emissions: The role of surface gustiness", Geophys. Res. Lett., 34, L15805, doi:10.1029/2007GL029971 (2007).

[5] Goudie, A.S., and Middleton, N.J., "Saharan dust storms: nature and consequences", Earth-Science Reviews, 56, 179-204 (2001).

[6] Laurent, B., Marticorena, B., Bergametti, G., Léon, J. F., and Mahowald, N. M., "Modeling mineral dust emissions from the Sahara desert using new surface properties and soil database", J. Geophys. Res., 113, D14218, doi:10.1029/2007JD009484 (2008).

[7] Levin, Z., Teller, A., Ganor, E., and Yin, Y., "On the interactions of mineral dust, sea-salt particles and clouds: A measurement and modelling study from the Mediterranean Israeli Dust Experiment campaign", J. Geophys. Res., 110, D20202, doi: 10.1029/2005JD005810 (2005).

[8] Miller, R., Tegen, I., and Perlwitz, J., "Surface radiative forcing by soil dust aerosols and the hydrologic cycle", J. Geophys. Res., 109, D04203, doi:10.1029/2003JD004085 (2004).

[9] Forster, P., et al., "Changes in Atmospheric Constituents and in Radiative Forcing" in Climate Change 2007: The Physical Science Basis. Contribution of Working Group I to the Fourth Assessment Report of the Intergovernmental Panel on Climate Change [Solomon, S., D. Qin, M. Manning, Z. Chen, M. Marquis, K. B. Averyt, M. Tignor and H. L. Miller (eds.)]. Cambridge University Press, Cambridge, United Kingdom and New York, NY, USA (2007).

[10] Houghton, J. T., Ding, W., Griggs, D. J., Noguer, M., van der Linden, P. J., and Xiaosu, D., "Climate Change 2001: The Scientific Basis, Contribution of Working Group I to the Third Assessment Report of the Intergovernmental Panel on Climate Change (IPCC)", Cambridge University Press, N. York (2001).

[11] Sokolik, I.N., Winker, D.M., Bergametti, G., Gillette, D., Carmichael, G., Kaufman, Y., Gomes, L., Schütz, L., and Penner, J. E., "Introduction to special section: outstanding problems in quantifying the radiative impacts of mineral dust", J. Geop hys. Res., 106, 18,015-18,027 (2001). 
[12] Pérez, C., Nickovic, S., Baldasano, J. M., Sicard, M., Rocadenbosch, F., and Cachorro, V.E., “A long Saharan dust event over the western Mediterranean: Lidar, Sun photometer observations, and regional dust modelling", J. Geophys. Res., 111, D15214, doi:10.1029/2005JD006579 (2006).

[13] Bösenberg, J., et al., “A European aerosol research lidar network to establish an aerosol climatology”, MPI-Report 317, Max-Planck Inst. für Meteorology, Hamburg, Germany (2003).

[14] Papayannis, A., et al., "Systematic lidar observations of Saharan dust over Europe in the frame of EARLINET (2000-2002)", J. Geophys. Res., 113, D10204, doi:10.1029/2007JD009028 (2008).

[15] Ansmann, A., Riebesell, M., Wandinger, U., Weitkamp, C., Voss, E., Lahmann, W., and Michaelis, W., “Combined Raman elastic-backscatter lidar for vertical profiling of moisture, aerosol extinction, backscatter and lidar ratio", Appl. Phys. B., 55, 18-28 (1992).

[16] Müller, D., Ansmann, A., Mattis, I., Tesche, M., Wandinger, U., Althausen, D., and Pisani, G., “Aerosol-typedependent lidar ratios observed with Raman lidar", J. Geophys. Res. 112(D16202), doi:10.1029/2006JD008292 (2007).

[17] Winker, D. M., Hunt, W. H., and McGill, M. J., “Initial performance assessment of CALIOP”, Geophys. Res. Lett., 34, L19803, doi:10.1029/2007GL030135 (2007).

[18] Mona, L., Pappalardo, G., Amodeo, A., D’Amico, G., Madonna, F., Boselli, A., Giunta, A., Russo, F., and Cuomo, V., "One year of CNR-IMAA multi-wavelength Raman lidar measurements in correspondence of CALIPSO overpass: Level 1 products comparison”, Atmos. Chem. Phys. Discuss., 9, 8429-8468 (2009).

[19] Pappalardo, G., et al., "EARLINET coordinated lidar observations of Saharan dust events on continental scale", IOP Conf. Series: Earth and Environmental Science, 7, 012002, doi:10.1088/1755-1307/7/1/012002 (2009).

[20] Pappalardo et al., "EARLINET correlative measurements for CALIPSO: first intercomparison results", submitted to J. Geophys. Res., (2009).

[21] Matthias, V., et al. "Vertical aerosol distribution over Europe: Statistical analysis of Raman lidar data from 10 European Aerosol Research Lidar Network (EARLINET) stations”, J. Geophys. Res., 109, D18201, doi:10.1029/2004JD004638 (2004).

[22] Draxler, R.R., and Hess, G. D., "An overview of the Hysplit_4 modeling system for trajectories, dispersion, and deposition”, Aust. Meteorol. Mag., 47, 295- 308 (1998).

[23] Nickovic, S., Kallos, G., Papadopoulos, A., and Kakaliagou, O., "A model for prediction of desert dust cycle in the atmosphere", J. Geophys.l Res., 106, 18,113-18,129 (2001).

[24] Mamouri, R.E., Amiridis, V., Papayannis, A., Giannakaki, E., Tsaknakis G., and Balis, D.S., "Validation of CALIPSO space-borne-derived attenuated backscatter coefficient profiles using a ground-based lidar in Athens, Greece", Atmos. Meas. Tech. Discuss., 2, 561-587 (2009)

[25] Huang, J., Minnis, P., Yi, Y., Tang, Q., Wang, X., Hu, Y., Liu, Z., Ayers, K., Trepte, C., and Winker, D., "Summer dust aerosols detected from CALIPSO over the Tibetan Plateau", Geophys. Res. Lett., 34, L18805, doi:10.1029/2007GL029938 (2007).

[26] Uno, I., Yumimoto, K., Shimizu, A., Hara, Y., Sugimoto, N., Wang, Z., Liu, Z., and Winker, D. M., “3-D Structure of Asian Dust transport revealed by CALIPSO Lidar and a 4DVAR Dust Model, Geophys. Res. Lett., 35, L06803, doi:10.1029/2007GL032329 (2008).

[27] Eguchi, K., Uno, I., Yumimoto, K., Takemura, T., Shimizu, A., Sugimoto, N., and Liu, Z., "Trans-pacific dust transport: integrated analysis of NASA/CALIPSO and a global aerosol transport model", Atmos. Chem. Phys., 9, 3137-3145 (2009). 